\title{
Gestores escolares e suas representações sociais de ciclos de aprendizagem
}

\author{
Laeda Bezerra Machado*
}

\section{Resumo}

Este artigo identifica e discute as representações sociais de ciclos de aprendizagem entre gestores do sistema municipal de Recife-PE. Entende-se representações sociais como teorias do saber comum, formas simples de as pessoas explicarem a realidade. Essas explicações guiam ações e comportamentos dos sujeitos. O estudo, de natureza qualitativa, foi desenvolvido em escolas da rede municipal de Recife-PE, utilizando como instrumentos para a coleta dos dados questionário e entrevista semiestruturada. Participaram do estudo 30 profissionais integrantes da equipe gestora de escolas municipais. Os dados foram organizados e discutidos com base na análise de conteúdo. Os resultados obtidos com a investigação da qual decorre este artigo revelaram os sentidos de ciclos que o grupo compartilha: imposição desse regime à rede, falta de infraestrutura das escolas para efetivação da proposta e precarização do trabalho docente. Esses sentidos interferem negativamente no processo de ensino-aprendizagem, impedindo um bom desenvolvimento do trabalho pedagógico nas escolas.

Palavras-chave: Ciclos de aprendizagem. Gestores escolares. Representações sociais.

\section{Introdução}

Os ciclos de aprendizagem caracterizam-se como a possibilidade de reorganização do tempo e espaço escolares, respeito ao ritmo de aprendizagem dos alunos e eliminação da repetência. No município de Recife - PE, os ciclos estão em vigor desde 2001 e vêm interferindo na estrutura e no funcionamento das unidades escolares. Essa nova forma de organização da escola, referendada pelas políticas públicas, procura romper com o sistema seriado e sua lógica excludente. Inquieta-

Professora Associada, vinculada ao Departamento de Administração Escolar e Planejamento Educacional, ao Programa de Pós-Graduação em Educação e ao Núcleo de Formação de Professores e Prática Pedagógica da UFPE, Recife-PE. Doutora em Educação. Bolsista de produtividade em pesquisa do CNPq. E-mail: laeda01@gmail.com 
ções e dúvidas, aliadas às preocupações acerca de como os sujeitos apropriam-se dos novos conhecimentos, levaram-nos a investigar as representações sociais de ciclos de aprendizagem de diferentes atores escolares. Este artigo, decorrente de parte de uma pesquisa mais ampla,${ }^{1}$ aborda as representações sociais de ciclos de aprendizagem entre gestores desse sistema municipal.

O termo "ciclo" está presente nas reformas educacionais brasileiras desde a década de 1930, designando um conjunto de anos de estudo. No entanto, a partir dos anos 1980, a palavra passou a ser utilizada com um significado diferente, de não retenção. A expressão aparece de modo mais recorrente no discurso educacional brasileiro a partir de 1984, com a implantação do Ciclo Básico de Alfabetização na rede estadual paulista. Esse ciclo visava à garantia de maior tempo de aprendizagem nos primeiros anos do ensino fundamental, de modo a reduzir as taxas de reprovação e evasão, constituindo-se como uma política inovadora no contexto da redemocratização do país. Devido à sua importância para a continuidade da aprendizagem, tornou-se referência para as propostas de correção de fluxo escolar implantadas no país a partir dos anos 1990. A atual Lei nº 9.394/96, Lei de Diretrizes e Bases da Educação Nacional, em seu artigo 23, incorporou a possibilidade de diferentes formas de organização da escola no país.

Em seus diferentes formatos, os ciclos procuram regularizar o fluxo de alunos, visando a assegurar uma aprendizagem efetiva. Eles têm se expandido e possibilitam a (re)organização do tempo e espaço escolares; o respeito aos ritmos e aos processos de aprendizagem dos alunos, bem como às fases do desenvolvimento humano; e a eliminação da repetência. Apresentam como objetivo principal garantir aos matriculados na educação básica a permanência na mesma escola, progressão nos estudos e tratamento pedagógico mais adequado às suas necessidades e aos níveis de aprendizagem. Na rede municipal de Recife-PE, o ensino fundamental está organizado em quatro ciclos, o primeiro com duração de três anos e ingresso a partir dos seis anos, seguido de três ciclos subsequentes, com duração de dois anos cada um. Conforme a proposta desse sistema (2002), somente é permitida a retenção dos alunos ao final de cada ciclo.

O tema ciclos de aprendizagem suscita uma diversidade de aspectos e intrincada rede de relações e implicações administrativas, pedagógicas e políticas. Essa proposta de organização da escola tem provocado discussões e mobilizado diversos autores, como Arroyo (1999, 2007), Barretto (2008), Barretto e Sousa (2004), Fetzner (2007), Freitas (2003), Gomes (2005), Glória (2002), Glória e Mafra (2004), Jacomini (2004), Machado (2007), Machado e Aniceto (2010), Mainardes (2007, 2008), Sousa (2007), para citar alguns. Nessa literatura, a preocupação em compreender os processos e as consequências da implantação dos ciclos de aprendizagem no sistema educacional brasileiro apresenta-se com diferentes enfoques. 
Barretto e Sousa (2004), Gomes (2005) e Mainardes (2007, 2008) procederam a levantamentos das experiências da implantação do sistema não seriado no país. Sob um enfoque diferenciado, Mainardes (2007) aborda, também, a evolução da política de ciclos, experiências práticas e análise da produção científica sobre a política de ciclos no Brasil. Gomes (2005), por seu turno, atém-se à descrição e análise das experiências da desseriação nos últimos 15 anos, enquanto Barretto e Sousa (2004) analisam essas experiências entre 1980 e 2002. Esses autores reconheceram a necessidade de maiores investigações sobre a temática.

Glória (2002), Glória e Mafra (2004) e Jacomini (2004), em seus estudos sobre os ciclos, focalizam a não retenção na escola e suas consequências. Glória (2002) evidencia a resistência de alunos e familiares ao novo sistema; Glória e Mafra (2004) destacam a recusa de professores à proposta de ciclos; por fim, Jacomini (2004) enfatiza os condicionantes que influenciam as concepções, resistências e atuação de docentes nos ciclos.

Os estudos de Arroyo (1999) e Fetzner (2007) tratam sobre a formação docente nos ciclos. Fetzner ressalta as possibilidades de transformação, mudanças na estruturação escolar e formação docente. Por sua vez, Arroyo realça o papel da formação desses docentes para acompanhar as mudanças provocadas pelas políticas de não retenção.

Sousa (2007) e Barretto (2008) focalizam o caráter inclusivo dos ciclos, que garantem o acesso à educação como direito de todos, chamando atenção para a necessidade de políticas públicas mais consistentes em termos de qualidade educacional para tornar efetivo esse direito. Barretto (2008) discute os impactos que diferentes formas de organização escolar em ciclos podem trazer para a qualidade do ensino, ao passo que Sousa (2007) dá mais ênfase às práticas de ensino e suas possibilidades de inclusão no sistema de ciclos.

Não ignorando a franca produção acerca da temática sobre ciclos no Brasil, dando continuidade a estudos anteriores (MACHADO, 2007; MACHADO; ANICETO, 2010) e reconhecendo o papel do gestor para a efetivação das políticas públicas implementadas no contexto escolar, com este estudo, buscou-se identificar as representações sociais de ciclos de aprendizagem construídas por gestores de escolas municipais de Recife - PE.

\section{Sobre a teoria das representações sociais}

De acordo com Moscovici, "as representações sociais são teorias, ciências coletivas destinadas à interpretação do real. Elas vão além do que é, imediatamente, dado na ciência ou na filosofia, da classificação de fatos e eventos” (1978, p. 47). 
Ao detalhar o processo de construção ou gênese de uma representação, o autor trata de dois momentos fundamentais na formação de uma representação social, a objetivação e a ancoragem. A gênese de uma representação constitui-se em uma atividade de transformação do não familiar em familiar, e esses dois conceitos (objetivação e ancoragem) explicariam como se processa essa atividade.

A objetivação é o processo cognitivo de transformar o que é novo, abstrato ou complexo em uma imagem significativa, incorporá-lo, materializá-lo num conceito, para compará-lo a algo que seja visto, percebido. Significa a tentativa de descobrir a realidade como ela de fato é. A objetivação constitui, ainda, a organização de uma rede conceitual visando à compreensão da realidade de maneira adequada. $\mathrm{O}$ processo de objetivação refere-se à operação formadora de imagem, tornando o conhecimento algo palpável, quase tangível, para entendê-lo.

A ancoragem é a incorporação definitiva desse novo objeto em nossos sistemas de referência. Diz respeito ao enraizamento do objeto novo e sua representação ao conhecimento social a partir de classificação e nomeação, amarrando-o a um pensamento preexistente. Com isso, o novo objeto de conhecimento pode ser descrito e distinto dos demais pelas características que lhe foram conferidas, tornando-se coerente e significativo aos valores sociais. A ancoragem constitui-se como um ponto de conexão entre o desconhecido e o pensamento já constituído, ou seja, as representações já existentes. Para Moscovici, "nos limites em que ela penetrou numa camada social, também se constitui como um meio capaz de influenciar os outros e, sob esse aspecto, adquire status instrumental" (1978, p. 113, grifo nosso). É como a domesticação do novo pressionado pelos valores sociais. Por ser feita na realidade social vivida, a ancoragem é a instrumentalização do saber, atribuindo-lhe, assim, um valor funcional.

Os processos de objetivação e ancoragem são complementares. Enquanto o primeiro constrói o real em si, o segundo lhe dá continuação ao atribuir significação ao objeto representado, garantindo uma estabilidade epistemológica e estabelecendo, assim, a própria representação social.

Moscovici afirma que as "representações sociais são entidades quase tangíveis, cristalizam-se incessantemente através de uma fala, um gesto, um encontro, ou seja, elas são fáceis de tipificá-las [sic] e difíceis de conceituá-las [sic]" (1978, p. 16). Jodelet (2001) completa, afirmando que as representações sociais são conhecimentos socialmente elaborados e partilhados por meio de interações que concorrem para a construção coletiva de uma realidade comum.

Em virtude da difusão dos ciclos de aprendizagem como política pública de correção de fluxo escolar, admite-se que essa nova forma de organização escolar constitui um fenômeno passível de construção de representações sociais. Neste 
estudo, procura-se identificar as representações sociais de ciclos de gestores escolares, buscando evidenciar o que se revelou de mais consensual ou compartilhado nessas representações.

\section{Os percursos da investigação}

A pesquisa que deu origem a este artigo é de natureza qualitativa. Utilizou-se como instrumentos para a coleta dos dados o questionário e a entrevista semiestruturada. O questionário permitiu uma caracterização dos participantes em relação à faixa etária, ao gênero, à função gestora assumida, ao tempo de experiência profissional como gestora ${ }^{2}$ e à forma de ingresso na função. A entrevista abordou as gestoras, basicamente, para interrogar-lhes sobre os ciclos de aprendizagem, sua implementação, suas práticas e repercussões na escola. As sessões de entrevistas foram individuais e os depoimentos, gravados mediante anuência do grupo pesquisado.

O campo empírico escolhido foi constituído por 18 escolas municipais, abrangendo as seis Regiões Político-Administrativas (RPAs) da cidade. A escolha desse campo ocorreu devido à implantação, em 2001, dos ciclos de aprendizagem nesse sistema de ensino. O critério estabelecido para a participação dos sujeitos na pesquisa foi integrar a equipe gestora das escolas.

Contamos com a participação de 30 profissionais, todas do gênero feminino, incluindo gestoras, vice-gestoras e coordenadoras pedagógicas. As participantes atuavam em escolas situadas em bairros diversos. Onze assumiram a função de gestora; nove, a de vice-gestora; e dez de coordenadora pedagógica. O grupo pesquisado estava com uma média de 45 anos de idade e cinco anos de exercício nas funções. As gestoras ingressaram na função por processo eletivo e as coordenadoras, por meio de seleção interna.

Os depoimentos foram analisados segundo a orientação de Bardin (1997) para a análise de conteúdo, uma técnica de interpretação do que foi expresso pelas participantes durante as entrevistas. Desenvolveu-se a análise em três etapas: a) leitura flutuante do material, visando a apreender as impressões iniciais expressas pelas participantes; b) agrupamento dos depoimentos pelo critério da similaridade; e c) organização dos depoimentos em categorias temáticas.

Dos depoimentos, emergiu um conjunto de categorias que expressam as representações sociais de ciclos de aprendizagem entre as gestoras escolares, a saber: a) imposição dos ciclos à rede municipal; b) proposta pedagógica promissora; c) processo avaliativo e relações com a insuficiência na aprendizagem. 


\section{Imposição dos ciclos à rede municipal}

Em primeiro lugar, as gestoras destacaram que a proposta de ciclos foi uma imposição "de cima para baixo" à rede, pois não houve uma consulta prévia aos envolvidos com o processo de ensino-aprendizagem na escola. Essa imposição provocou dúvidas, falta de adesão à proposta, controvérsias e descrença nesse novo sistema de organização escolar. Eis alguns trechos das falas das gestoras:

[...] eles foram impostos [...]. Os professores receberam a notícia que os ciclos seriam implantados e não houve uma consulta prévia [...] não houve uma preparação pra essa mudança [...] é uma transformação muito grande que ocorreu, só que ela veio imposta [...] (Ges. 23). ${ }^{3}$

Não houve [...] um estudo, uma avaliação prévia, nós sabemos que [...] o sistema de ciclos foi implantado no Rio Grande do Sul em Porto Alegre [...] mas foram oito anos de estudos prévios pra que pudesse ser implantado. Aqui no Recife, não. Foi simplesmente a mudança de política pedagógica, porque ganhou o partido "A", ganhou o partido "B" [...] (Ges. 30).

O ciclo, quando chegou na nossa mão, foi uma proposta imposta, ela não foi trabalhada, tá certo, ela colocou e pronto: "Façam isso". Então, é mal interpretada até. Por incrível que pareça, até os gerentes, os gerentes que tem na, no Reitor, eles sentem dificuldade (Ges. 6).

Conforme revelaram as entrevistadas, o modelo de implantação constituiu um dos maiores entraves à adesão dos professores. Para elas, os professores foram desconsiderados, pois não conhecem os fundamentos da proposta. Além disso, as condições de trabalho não são favoráveis à sua efetivação. Assim, acaba-se por não acreditar que é possível fazer diferente no novo sistema.

Para as participantes da pesquisa, a falta de êxito dos ciclos de aprendizagem na rede municipal está relacionada à sua imposição, o que impediu sua compreensão por parte dos professores, a fim de que pudessem trabalhá-los de maneira adequada, sem resistências. Aliadas à imposição, a infraestrutura precária, a ausência de docentes fixos nas equipes escolares e a rotatividade de estagiários comprometem a proposta. A esse respeito, as gestoras comentaram:

[...] Acho que o ciclo se torna um paradoxo no momento em que o professor não tenha 0 conhecimento do que seja realmente o ciclo e acha que o aluno não tem que chegar a um determinado ponto naquele ano, então, nesse ponto o ciclo é negativo [...] (Ges. 5).

[...] Eu até acreditaria no ciclo, mas na rede, não, porque o ciclo precisa de uma estrutura muito maior da qual a rede, ela ainda não proporciona essa estrutura, impôs e não deu condições para se trabalhar (Ges. 10).

Como consequência da imposição, as gestoras admitem que os professores não concedem credibilidade aos princípios orientadores da proposta, e, então, a mudança, ou melhor, a sua aceitação fica impedida, por não haver um maior com- 
prometimento do sistema com a formação continuada desses profissionais. A esse respeito, Arroyo (1999) e Fetzner (2007) também se manifestam, reforçando a formação continuada e as mudanças na estrutura física das instituições como fatores fundamentais para o êxito da proposta de ciclos. O que se pode depreender dos depoimentos dessas profissionais é que a imposição dos ciclos à rede municipal, embora já tenham se passado dez anos, foi ancorada como um fator de impedimento à sua efetivação e viabilidade.

O sentido compartilhado de imposição da proposta de ciclos à rede e a crítica a esse modelo já vêm sendo comuns em diversos trabalhos. Machado e Aniceto (2008) constataram que, devido à imposição, a maioria dos professores considerou a implantação da proposta de ciclos como um retrocesso. Referindo-se ao contexto nacional, Mainardes (2007) explicita que a implantação dos ciclos de "cima para baixo" tem sido determinante para que os profissionais sintam-se meros executores das políticas públicas. Freitas (2003) externa sua preocupação com a adoção em massa de política pública. Segundo ele, a implantação do regime poderia ser progressiva nas escolas, de forma experiencial. Agindo desse modo, as autoridades estariam demonstrando mais respeito à autonomia das instituições e às decisões tomadas pelos seus responsáveis imediatos.

\section{Proposta pedagógica promissora}

Apesar dos obstáculos decorrentes da imposição, as gestoras reconhecem que a proposta de ciclos têm mérito, pois, além de contribuir para diminuir a distorção idade/série, possibilita o acompanhamento individualizado a cada aluno, uma avaliação constante e mais coerente com o desenvolvimento dos estudantes. É o que revelam nos trechos dos depoimentos, a seguir:

A minha opinião pessoal é que [...] o aluno tem um tempo pra... O tempo de aprender, um ritmo de aprender, cada aluno é uma, não sei, que tem um tempo individual de aprendizagem, então eu acho que nesse aspecto foi, foi muito válido na educação (Ges. 12).

O ciclo dá oportunidade pra que o aluno tenha o seu tempo de aprendizagem suficiente, que a gente realmente avalie o aluno de acordo com o grau de dificuldade enfrentada em cada ciclo que ele passa (Ges. 26).

As participantes afirmam que a proposta pedagógica de ciclos é promissora, por possibilitar a organização das turmas, respeitando o ritmo de aprendizagem dos alunos, bem como por prever uma avaliação que considere o seu desenvolvimento numa perspectiva inclusiva. Suas colocações coincidem com o que é dito por Barretto (2008) e Sousa (2007), quando argumentam sobre a possibilidade de inclusão a partir dos ciclos. Segundo elas, a proposta é inclusiva, na medida em que garante o 
direito à permanência na escola. Contudo, essas autoras reconhecem os obstáculos para com a efetiva qualidade da educação e chamam a atenção para a necessidade de políticas públicas consistentes que permitam a efetivação desse objetivo.

As gestoras enfatizam o caráter significativo e promissor da proposta, que estimula e incentiva trabalhos lúdicos e dinâmicos que propiciem o desenvolvimento cognitivo e social do aluno, melhorando e estimulando sua autoestima. Além de reconhecerem que a proposta valoriza o aluno, seu saber, as participantes observam que:

[...] os ciclos, eles [...] dão essa abertura, eles dão essa condição, essa abertura pra você estar sempre buscando novas alternativas, novos projetos, então, eu acho que esse é o grande, a grande modificação (Ges. 4).

É um estilo de aprender diferente, já que... todo mundo é capaz de aprender, eu acho, o ciclo coloca isso, todos são capazes de aprender, que a gente precisa encontrar a maneira mais adequada pra que aquele menino possa desenvolver (Ges. 22).

Foi solicitado às gestoras que explicitassem o que seria esse caráter mais lúdico e dinâmico da proposta de ciclos. Sobre esse aspecto, elas destacaram que a proposta possibilita o desenvolvimento de atividades diferenciadas a serem realizadas pela própria escola, tais como alternativas relacionadas a setores externos, como parcerias com universidade, ONGs, teatro, biblioteca e outros, que permitem o desenvolvimento de trabalhos extraclasse, com as famílias, aulas-passeio, atividades de informática; além de alternativas da própria escola, como recreio dirigido, atividades lúdicas, passeios, jogos, concursos, filmes, literatura infantil, desenvolvimento de diversos projetos didáticos. Ainda, fizeram referência à mobilização da equipe pedagógica das escolas para a alfabetização, o acompanhamento dos alunos e o apoio aos professores, com utilização de materiais diversos, como ábaco, material dourado, entre outros. A seguir, são expostas algumas de suas falas:

Ah, são tantas! A gente trabalha bastante a questão do lúdico, tem a professora da biblioteca que trabalha com menino com, com projetos, com leituras, com concursos, agora vai ter no concurso o recital de poesias que eles amam, tem também aberto o concurso de a melhor poesia, o melhor desenho [...] com entrega de, de prêmios, com entrega de... troféus, e o interessante é o que eles amam, eles gostam do lúdico, quando, quando você conta uma história pra o menino ele, ele viaja, e eu faço recreio dirigido [...] (Ges. 5).

[...] atividades diferenciadas com os alunos que apresentam problemas de aprendizagem [...] eles conseguiram aprender e trabalhar jogos de estratégia, trabalhar com material dourado, trabalhar com ábaco, tá sendo muito legal pra gente, pra eles também (Ges. 11).

No entanto, as gestoras vão elencando aspectos que parecem minar o caráter promissor da proposta: falta de apoio da gestão do sistema, precárias condições de trabalho na escola, inexistência de parceria com as famílias. Do que falaram, pode-se 
depreender que compartilham uma representação social positiva da proposta em si, mas que acaba sendo inviabilizada pelas condições gerais de trabalho nas escolas.

\section{Processo avaliativo e relações com a insuficiência na aprendizagem}

As gestoras relatam que a proposta de ciclos provocou mudanças negativas, como a não retenção dos alunos na escola, algo que tem desmotivado os professores. Consideram, ainda, que os ciclos não admitem a possibilidade de reprovação do aluno, o qual é promovido independentemente do seu avanço na aprendizagem. Segundo seus depoimentos, a promoção automática do aluno constitui um prejuízo para o professor, que se sente bastante desmotivado ao ter que aprovar todos, os que aprenderam e também aqueles que não conseguiram aprender. Para elas, a avaliação nos ciclos é representada como complicada, não formativa e desmotivadora tanto para alunos como para professores e famílias. Eis alguns trechos de suas falas a esse respeito:

a falta de motivação [...] tanto a motivação dos professores, quanto dos alunos porque eles não têm essa questão da [...] aprovação [...] e acabam sendo aprovados do mesmo jeito que aqueles que não sabem, então é um ciclo realmente, um ciclo que tá se tornando um ciclo vicioso, os alunos não têm, não aprendem, mesmo assim são aprovados [...] (Ges. 11).

Eu não estou de acordo com uma avaliação de faz de conta, que tudo pode e deve ser aceito, arrastamos um problema para o futuro, para o próprio aluno e a sociedade. Que adianta tanta gente sendo aprovada sem saber! Para mim isso prejudica demais (Ges. 17).

$\mathrm{Na}$ esteira da discussão sobre a avaliação nos ciclos, as entrevistadas afirmam que, contraditoriamente ao que advoga o sistema municipal, o aluno tem sido pouco interessado em investir no seu processo de aprendizagem, algo prejudicial e complexo para o trabalho do professor. Alguns trechos de seus comentários são transcritos na sequência:

[...] eu digo a você, nem o próprio professor aceita bem essa questão do ciclo, né, porque tem menino que chega no final de ano e ainda está naquele, naquela marcha muito lenta em relação ao ensino-aprendizagem e tem que passar, o professor se sente prejudicado. Ele não quer levar adiante o problema, mas tem que levar (Ges. 1).

[...] o que melhorou, eu não sei assim dizer tanto, talvez complicou o trabalho do professor no sentido de quando não, não se faz a prova, fica mais difícil é avaliar porque passa por uma avaliação constante... (Ges. 8).

[...] se a turma já era heterogênea fica hiper-heterogênea e fica difícil pro professor dominar, um exemplo, trazer um menino que veio de um ciclo um, não conseguiu, vai pro dois, três, aí quando chega muitos vão deixando pra depois, pra o outro professor talvez é, tente consertar, aqueles que são mais compromissados vão fazer isso, outros vão deixar adiante e o menino vai passando e isso vai tornando um, uma bola de neve (Ges. 13). 
Dos depoimentos, pode-se inferir que os ciclos propõem uma nova forma de trabalho, que não tem sido viabilizada na prática. Salienta-se que as representações sociais constituem um conjunto estruturado de informações, crenças, opiniões e atitudes que orientam as práticas e condutas dos sujeitos em seus grupos de pertença. Assim, é possível afirmar que as representações dos ciclos centradas na desmotivação decorrem da mudança mais radical que a proposta provocou na escola: o fim da retenção.

Em decorrência da não retenção, as gestoras sinalizam que os ciclos pressupõem uma aprendizagem deficitária, insuficiente e fraca. Segundo elas, a maior liberdade proporcionada aos alunos nos ciclos acaba sendo prejudicial, na medida em que provoca o desinteresse. Admitem que, cientes de que serão aprovados, os alunos e suas famílias perderam o interesse pelo investimento nas aprendizagens escolares. Eis alguns exemplos:

Não adianta ter a promoção automática se os alunos... Eles não tão aprendendo o que era pra aprender [...]. Ele sai como se fosse um analfabeto funcional. Os alunos hoje, eles são pagos pra estudar devido às bolsas [...] que existem, eles são pagos pra estudar, mas eles não tão exercendo a função deles mesmo que é de estudante, aí tá faltando (Ges. 10).

[...] Essa aprendizagem está muito difícil. A aprendizagem dos alunos está muito deficiente, muito mesmo, eles não estão conseguindo compreender [...]. O professor, aos poucos, já tá perdendo as esperanças de ver uma sala ideal, uma sala perfeita para o nível que eles estão ensinando, é muito difícil pra eles e, pra gente, de uma maneira geral (Ges. 11).

[...] essa avaliação, ela, depois dessa implantação, a gente começa a perceber (pausa) a gente começa a perceber que é... não houve uma mudança a nível de aprendizagem, tá certo?! Não houve uma mudança significativa, não. Não consigo, não consigo perceber, vamos dizer, um resultado eficaz, dizer não! O ciclo realmente, ele veio pra mudar, não é mudar só de passar de um número pra um registro, não, ele veio realmente para uma aprendizagem, né, muito mais eficaz. Isso ainda eu não tenho percebido, não, não tenho percebido (Ges. 19).

Os resultados obtidos com a investigação da qual decorre este artigo revelaram como representações sociais de ciclos pelo grupo: imposição desse regime à rede, falta de infraestrutura das escolas para efetivação da proposta e precarização do trabalho docente. Esses sentidos interferem negativamente no processo de ensino-aprendizagem, impedindo um bom desenvolvimento do trabalho pedagógico nas escolas. As participantes deram ênfase à dupla não retenção/insuficiência da aprendizagem no sistema de ciclos como o principal elemento de desmotivação dos professores para com a proposta. Elas reprovam por completo a promoção independente dos avanços da aprendizagem.

Por outro lado, as gestoras não deixaram de reconhecer que, quando bem planejada, participada e assumida, de modo responsável, pelo sistema, a proposta pode ser promissora. Esse caráter positivo pode ser evidenciado devido ao fato de a proposta valorizar e reconhecer os saberes dos alunos, estimular a flexibilidade do 
trabalho do professor e possibilitar uma avaliação formativa que enfatiza aspectos qualitativos, extinguindo os rótulos e estimulando as competências dos estudantes. Logo, o sentido compartilhado pelas gestoras é o seguinte: a proposta em si é boa, mas a rede tem problemas de toda ordem que impedem seu êxito.

\section{Considerações finais}

Do exposto neste artigo, pode-se inferir que os gestores escolares do município do Recife-PE construíram uma representação social de ciclos de aprendizagem que é ambivalente, ou seja, articula aspectos positivos e negativos da proposta. Como afirma Gilly (2001), essas ambivalências das representações sociais mesclam, num todo coerente, as contradições entre ideologia e realidade, assegurando a função de legitimação do sistema e justificação de práticas. As representações sociais de ciclos dos gestores estão permeadas de contradições que aglutinam seu lado interessante, bom, positivo.

O estudo realizado sinalizou a necessidade de um aprofundamento com outros atores inseridos no sistema de ciclos para melhor compreensão das representações sociais dessa temática, buscando outras vozes, outros sentidos atribuídos à proposta. Esse tem sido o empreendimento atual, pois, como afirma Sá (1998), as representações são difusas, fugidias, multifacetadas, o que dificulta sua identificação. Tem se ampliado o estudo, dando ênfase às relações entre práticas pedagógicas bem-sucedidas nos ciclos de aprendizagem e as representações sociais dos professores sobre esse sistema.

\section{School administrators and social representations of learning cycles}

\section{Abstract}

This article identifies and discusses the social representations of learning cycles among managers of Recife-PE municipal system. It is understood as a social representations theory of common knowledge, simple ways people explain reality. These explanations guide actions and behaviors of the subjects. The study, of a qualitative nature, was developed in municipal schools of Recife-PE, using as instruments for data collection questionnaire and semi-structured interview. The study included 30 professional members of the management team of municipal schools. The data were organized and discussed based on content analysis. The results obtained from the investigation which follows this article revealed the sense of cycles that group share: the imposition of the scheme to the network, lack of school infrastructure to execute the proposal and precariousness of teaching. These senses interfere negatively in the learning process by preventing a successful development of pedagogical work in schools.

Keywords: Learning cycles. Management school. Social representations. 


\section{Notas}

1 Título da pesquisa: Ciclos de aprendizagem: um estudo das representações sociais dos atores escolares e futuros professores dos anos iniciais. Financiamento: CNPq/Facepe 2009-2011.

2 Embora não tenha havido intenção de investigar apenas o gênero feminino, o próprio campo deu essa configuração ao grupo participante.

3 Utiliza-se a expressão "Ges.", para abreviar o termo "gestora", seguida do número do protocolo de entrevista realizada com cada participante.

\section{Referências}

ANICETO, Rosimere de Almeida; MACHADO, Laêda Bezerra. Ciclos de aprendizagem: sentidos e significados atribuídos pelos professores. In: CONGRESSO DE INICIAÇÃO CIENTÍFICA (CONIC) DA UFPE, 16, JORNADA DE INICIAÇÃO CIENTÍFICA DA FUNDAJ, 4, 2008, Anais... Recife: Editora EDUFPE, 2004. p. 21-36. (CD-ROOM).

ARROYO, Miguel. Ciclos de desenvolvimento humano e formação de educadores. Educação $e$ Sociedade, v. 1, n. 68, p. 143-162, dez. 1999.

Ciclos de formação. O que pesquisar e refletir?. In: FETZNER, Andréa Rosana. (Org.). Ciclos em Revista: Implicações curriculares de uma escola não seriada. 1. ed. Rio de Janeiro: Wak Editora, 2007, v. 2, p. 17-34.

BARDIN, Lawrence. Análise de conteúdo. [s.1.]: Edições 70, 1997.

BARRETTO, Elba Siqueira de Sá. As escolas em ciclos e seus resultados no processo ensino-aprendizagem. Ciclos em Revista, v. 4, n. 2, p. 195-212, 2008.

BARRETTO, Elba Siqueira de Sá; SOUSA, Sandra Zákia. Estudos sobre ciclos e progressão escolar no Brasil: uma revisão. Educação e Pesquisa, São Paulo, v. 30, n. 1, p. 31-50, jan./abr. 2004.

BRASIL. Lei $n^{\circ}$ 9.394, de 20 de dezembro de 1996. Lei de Diretrizes e Bases da Educação Nacional. Disponível em: http://bd.camara.gov.br/bd/bitstream/handle/bdcamara/2762/ldb_5ed.pdf

FETZNER, Andréa Rosana (Org.). Ciclos em revista: implicações curriculares de uma escola não seriada. Rio de Janeiro: Wak, 2007. v. 2. 148p.

FREITAS, Luiz Carlos de. Ciclos, seriação e avaliação: confronto de lógicas. São Paulo: Moderna, 2003. (Coleção Cotidiano Escolar).

GILLY, Michel. As representações sociais no campo da educação. In: JODELET, Denise. (Org.). Representações sociais. Rio de Janeiro: EDUERJ, 2001. p. 321-342.

GLÓRIA, Dilia Maria. A escola dos que passam sem saber: a prática da não retenção na narrativa de alunos e familiares. In: REUNIÃO ANUAL DA ANPED, 25, 2002, Caxambu, MG. Anais... Caxambu, MG, 2002. p. 61-76.

GLÓRIA, Dilia Maria; MAFRA, Leila. A prática da não retenção na narrativa de professores do ensino fundamental: dificuldades e avanços na busca do sucesso escolar. Cadernos de Educação e Pesquisa, São Paulo, v. 30, n. 2, p. 231-250, maio/ago. 2004.

GOMES, Carlos Alberto. Desseriação escolar: alternativa para o sucesso? Ensaio: Avaliação, Políticas Públicas, Educação, Rio de Janeiro, v. 13, n. 46, p. 11-38, jan./mar. 2005. 
JACOMINI, M. A. A escola e os educadores em tempos de ciclos e progressão continuada: uma análise das experiências no estado de São Paulo. Cadernos de Pesquisa, São Paulo, v. 30, n. 3, p. 401-418, set/dez. 2004.

JODELET, D. Representações sociais: um domínio em expansão. In: JODELET, D. (Org.). As representações sociais. Rio de Janeiro: Eduerj, 2001. p. 17-44.

MACHADO, Laeda Bezerra. Eles "passam de bolo" e ficam cada vez mais analfabetos: discutindo as representações sociais de ciclos de aprendizagem entre professores. Revista Psicologia da Educação, São Paulo, v. 24, n. 24, p. 111-128, 1. sem./2007.

MACHADO, Laeda Bezerra; ANICETO, Rosimere de Almeida. Núcleo central e periferia das representações sociais de ciclos de aprendizagem entre professores. Ensaio: Avaliação e Políticas Públicas em Educação, Rio de Janeiro, v. 18, n. 67, p. 345-363, 2010.

MAINARDES, Jefferson. Reinterpretando os ciclos de aprendizagem. São Paulo: Cortez, 2007.

. A organização da escolaridade em ciclos no Brasil: uma análise de pesquisas sobre processos de implementação. Revista Brasileira de Política e Administração da Educação, v. 24, ]n. 1, p. 13-29, jan./abr. 2008.

MOSCOVICI, Serge. A representação social da psicanálise. Rio de Janeiro: Jorge Zahar, 1978.

RECIFE. Secretaria de Educação. Proposta pedagógica da rede municipal de ensino do Recife: construindo competências. Recife: Secretaria de Educação, 2002.

SÁ, Celso P. de. A construção do objeto de pesquisa em representações sociais. Rio de Janeiro: Eduerj, 1998.

SOUSA, Sandra Zakia. Avaliação, ciclos e qualidade do ensino fundamental: uma relação a ser construída. Estudos Avançados, v. 21, n. 60, p. 27-44, 2007. 